\title{
What is the Likelihood of the Social Safety Net Programme to Reduce Poverty in Ndop and Soulede -Roua in Cameroon?
}

\author{
Vukenkeng Andrew Wujung (Ph.D) \\ Associate Professor of Economics, Faculty of Economics and Management Sciences, The University of \\ Bamenda, P.O box 39, Bambili, Cameroon \\ Vachuiden Jacob Mbueh \\ Faculty of Economics and Management Sciences, The University of Bamenda, P.O box 39, Bambili, Cameroon
}

\begin{abstract}
This paper sought to make a comparative analysis of the effects of the Social Safety Net Programme on poverty outcomes in Ndop and Soulede-Roua in Cameroon. Data was collected with the aid of questionnaires which were administered to 150 respondents in Ndop and 150 respondents in SouledeRoua. The study employed descriptive statistics and inferential statistics in analysing the data. Results from the analysis showed that participation in the Social Safety Net Programme in both localities has a negative but insignificant effect on the likelihood of reducing poverty though the effect was more important in Soulede-Roua than in Ndop. Furthermore, the unemployed, household size, widowed and no educational level were found to have a positive significant influence on the likelihood to reduce poverty. From a policy perspective, an important conclusion is that there is need for the government to improve on the efficiency of the programme by overcoming all the challenges inherent in the pilot experiment. Practically, government should use a participatory approach in the management of the project.
\end{abstract}

Key Words: Social Safety Net Programme, Poverty outcomes,Probit, Cameroon

DOI: $10.7176 / \mathrm{DCS} / 10-8-07$

Publication date:August $31^{\text {st }} 2020$

\section{INTRODUCTION}

The world recently has witnessed an improvement in Social Safety Net protection Programme (SSNP)as the new focus is on the efforts to reduce poverty around the world especially in rural areas (World Bank, 2003). Access to adequate social protection is recognized by international labour standards as well as the United Nations as a basic right for all. In recent times, the global focus has been on food security and poverty alleviation. This is being made in response to the increasing food insecurity and poverty in the world. The incidence of food insecurity and poverty is devastating particularly in the developing countries and in terms of food insecurity, 852 million people worldwide are still chronically underfed. In Africa, an estimated 200million (27.4 percent) people are famished (Babatundeet al., 2007).

In 2007, monetary poverty in Cameroon affected 40 percent of the population and 46 percent of persons under 18. Between 2001 and 2007, the number of poor children increased from 3.6 to 4.1 million. There is a wide gap between urban and rural children regarding the incidence of poverty, 16 and 60 percent, respectively (NguetseTegoum, 2011). The Adamawa, East, North, Far North and North West regions of the country are regions with persistently high rates of income poverty. Child poverty constitutes a stigma which prevents children from asserting themselves and impedes the protection and realization of their rights. Certain social practices (early marriage, early pregnancy, and child labour) continue to prevail in these regions as perceived survival strategies.Several studies have been made and books are published on productive safety net Programme. Assessments and impact evaluations have been made by different stakeholders working in the area. For instance, Judit and Matt, (2011), emphasizedthe remarkable achievements of PSNP starting from the efficiency of community targeting systems. They have noted that the timely payments made sure that people are not forced to sell their productive assets.

However, the past decades of large scale food aid deliveries have done little to prevent households' asset depletion because of ignorance of incorporating these aids with natural resource management (Devereux et al., 2006). Recognizing this, the government of Cameroon changed the emergency food based assistance to multi-year PSNP in 2011 when Boko Haram activities increased in the Far North region of Cameroon that provide transfers to food insecure households with the aim of breaking dependency on food aid in the long term. These transfers are expected to be used partly to meet immediate consumption needs, but also partly invested in farming and enterprise activities (Tsafack, 2013). SouledeRoua in the Far North region of Cameroon is one of the chronically food insecure areas where Productive Social Net Programme(PSNP)has actively been implemented together with other food security Programme (OFSP) to change the life of households. One of the approaches adopted for enabling the farming households of the area to protect asset depletion at household level and invest in Sustainable Land Management (SLM)practices to increase productivity of their land is the PSNP. Even though several attempts have been made to evaluate the general impact of PSNP countrywide, there are limited empirical evidences whether or 
not the programme efforts have the intended effect on asset accumulation (asset protection from depletion) and investment in SLM by programme participants. Therefore, this paperconduct a comparative analysis of the effects of social safety nets programme on poverty outcomes in the two piloted areas of North West and Far North Regions of Cameroon. The second section of this paper reviews literature linking Social safety net programme and poverty outcomes. Section three is devoted to method of analysis. The empirical findings are presented in section four and section five concludes the paper with some policy recommendations.

\section{LITERATURE REVIEW}

The World Development Report 2000/1 focuses on empowerment, security, and opportunity (World Bank, 2000). The World Bank's Social Protection Strategy incorporates several familiar instruments - labour market interventions, social insurance (including pensions), and social safety nets (including social funds) - that relate to the second of these concepts, but goes further. Social protection is currently defined by the World Bank as "public interventions to assist individuals, households, and communities better manage risk, and to provide support to the critically poor" (Holzmann and Jørgensen, 2000). Social protection can therefore be seen as a broader concept than social safety nets, which was the third prong of the 1990 world Development Report on Poverty. The expanded approach invokes social risk management as an underlying conceptual framework. It argues that social protection should move beyond the residualist and reactive nature of conventional safety nets, to reduce and mitigate the risk and insecurity that have recently been recognized as central to the experience of poverty and wellbeing.

The Oversees Development Institute (ODI) proposes a similar definition: "Social protection refers to the public actions taken in response to levels of vulnerability, risk and deprivation which are deemed socially unacceptable within a given polity or society" (Norton et al., 2000). This definition addresses two categories of needs: absolute poverty or deprivation, and vulnerability of the poor or non-poor to exogenous or life-cycle shocks. In contrast to the inclusive definition favoured by the World Bank, however, the ODI conceptualises social protection almost as narrowly as social safety nets. The ODI ${ }^{\text {ee }}$ definition refers to the protection of those who fall temporarily or persistently under levels of livelihood deemed unacceptable, rather than the promotion of a general standard of opportunity and livelihood for all citizens" (Norton et al. 2000).

Recent research on multi-poverty in Cameroon was inspired by theoretical advances in the area. The National Institute of Statistics (INS, 2002) undertook to draw up two poverty profiles from the results of the Cameroon household (ECAM II) survey, one monetary and the other non-monetary. The methodology used in the latter case was the sum of privative scores obtained by assigning the code 0 if the person did not possess a commodity item and the code 1 if he/she did. The results showed that $40 \%$ of the households studied, essentially from rural areas and composed mainly of farmers did not possess 12 out of the 14 commodities targeted. Using the same methodology but expanding the number of poverty dimensions, Tachi (2003) demonstrated that 5.21\%of the Cameroonian population suffered from all forms of poverty.

Studies carried out in Ethiopia have shown that food for work Programme (which had a similar aim with PSNP except that PSNP focuses continuously on selected households over several years and it will eventually be phased out) had a positive influence on the probability of fertilizer adoption (Sosina and Holden, 2007). However, other studies have indicated that it may have negative impact on agricultural intensification (Barrett et al., 2004), short-term soil conservation measures (Berhanu and Swinton, 2003), informal risk sharing (Dercon and Krishnan, 2004) and growth of livestock holdings (Gilligan and Hoddinott, 2007). Different studies have been carried out on different issues regarding PSNP in Ethiopia. To list a few: Gilligan et al. (2008) conducted a study to analyse the Ethiopia's PSNP and its linkage after one and half a year since the implementation of the programme. According to their study, the programme had a significant positive impact on participants ${ }^{\text {ee }}$ food security; borrowing for productive purposes; use of improved technologies and creating non-farm own businesses compared to the control groups when the PSNP was only complemented with other food security programme (OFSP). However, when the participants received only PSNP transfers of ETB 90 per month or more per individual without access to OFSP, their study shows that the programme reduces the likelihood of households' very low caloric intake and improves mean calorie availability. They also found no evidence for the disincentive effects on the reduction of labour supply to wage employment or private transfers. However, their study shows that relative to the control group, participants did not experience faster asset growth even when the PSNP was complemented with OFSP.

Another study by Njong (2008) applied the Fuzzy Set theory with the aim of identifying the sources of multipoverty as well as its variations in space and time in Cameroon between 1996 and 2001. He arrived at the conclusion that the incidence of multi-poverty rose from $42.08 \%$ to $50.39 \%$. But he also found that while the contribution of urban and semi-urban areas to multi-poverty rose between the two dates that of rural areas did not. This is a finding that can be explained by migration of rural populations to urban and semi-urban areas.

The basic criticism levied against the three studies mentioned above has to do with the arbitrary nature that they fixed poverty thresholds on the basic indicators. On the other hand, there are even more studies based on the inertia approach, which was inspired by statistical mechanics and used the techniques of factor methods. The first 
is the study by Ningaye et al. (2007) which used the Structural Equation Modeling to study the impact of cultural conditioning on multi-poverty. The study arrived at the conclusion that the differential observed in the distribution of multi-dimensional poverty was significantlyinfluenced by the cultural diversity of the country's population.

The second study is that by Foko et al. (2007) which, while following objectives that are close to ours, obtained weightings on indicators by using the Multiple Factor Analysis (MFA). But the methodology they used can be criticized on two grounds: Firstly, the MFA deals with several sets of variables with the aim of highlighting those of these sets for which the structures of individuals are on the whole identitical. That is why, when there are only two sets of variables, one is considered explained and the other explanatory (Diday et al., 1982). Secondly, the MFA algorithm has been conceived primarily for quantitative variables and can be adapted to qualitative variables only at the price of intermediate computations (Foko et al. 2007). The present study uses the probit model which is directly applicable to binary variables to investigate the likelihood of social safety net programme on poverty while controlling for other factors.

The late 1990s saw a growing disillusion with social safety nets, which were seen as welfarist compensatory mechanisms that reduced the poor to passive recipients of ,handoutse and made no effective contribution to broader development goals or to sustainable poverty reduction. Social funds, for example, which have been implemented in many Latin American and African countries since the 1980s, were intended to be demand-driven at the local level, building on community initiatives and resources, and participatory in design and implementation. However, several independent evaluations of social funds have been cautious or sceptical about their impacts and the extent to which they were genuinely participatory or empowering (Stewart and van der Geest 1995; Tendler and Serrano, 1999).

A multi-country process of Consultations with the poor highlighted the importance of income variability and livelihood insecurity as a previously neglected feature of poverty (Brock 1999; Narayan et al. 1999). Uncertainty encourages the poor, for whom the cost of downside risk is highest, to adopt risk-spreading strategies that reduce income fluctuations rather than maximizing expected returns (Siegel and Alwang 1999), but this behaviour itself, though rational, contributes to keeping poor people poor. In response to these insights, more ambitious approaches have been proposed which would reduce risk and vulnerability ex- ante rather than being reactive responses to livelihoods shocks ex- post, and which would address the causes of poverty and vulnerability as well as the consequences.

The literature review above reveals that there is wide store of knowledge and studies in the domain of analysis of poverty outcomes. Studies focusing on determinants of poverty in general are numerous. However, the social safety network programme is not unique to Cameroon. It has been implemented in other African countries. However, very few empirical studies have analysed the effect of this social safety net programme on poverty outcomes in countries where they were implemented. Empirical studies focusing on the impact analysis of such a programme are still very scarce. In the Cameroonian context, such studies are practically inexistent. It is on this ground that the present paper analyses the probable effects of social safety net programme on poverty outcomes in the two pilot localities in Cameroon.

\section{METHODOLOGY}

This paper seeks to investigate the effect of social safety net programme on poverty in two localities of Cameroon. In order to meet with the stated objective, the paper specified a Probit model as follows:

POV $=\mathrm{f}(\mathrm{LOC}, \mathrm{SSNP}, \mathrm{OCCU}, \mathrm{SEX}$, AGE, MS, HHS, EDUC)....

The econometric form of the above model is given by equation 2 below:

$$
\begin{aligned}
& P O V=\beta_{0}+\beta_{1} L O C+\beta_{2} S S N P+\beta_{3} O C C U+\beta_{4} S E X+\beta_{5} A G E+\beta_{6} M S+\beta_{7} H H S+ \\
& \beta_{8} E D U C+\varepsilon
\end{aligned}
$$

Where:

POV represents poverty status measured by a dichotomous variable that is 1 if the individual income was below the minimum wage and 0if otherwise.

LOC is locality also captured by a binary variable ( 1 if Ndop and 0 if SouledeRoua).

SSNP represents participation in the social safety net program

OCCU is occupation captured by a categorical variable with $1=$ unemployed, category 2 = civil servant, category $3=$ Self-employed .

SEX is the gender of the respondents and is measured as a binary variable with 1 representing male and 0 , female. AGE represents the age group of the respondents measured as a polychotomous variable where category $1=$ less than 30 ; category $2=30-50$ years; category $3=51-80$ years; category $4=$ above 80 years.

MS is marital status which is a categorical variable where category $1=\operatorname{single}, 2=$ monogamous, $3=$ polygamous, $4=$ divorced, and $5=$ widowed

HHS is the household size representing the number of people in the household measured as a categorical variable where category $1=1-5$; category $2=6-10$; category $3=11-15$; category $4=16-20$; category $5=$ above 20 .

EDUC stands for level of education which is categorical where category 1 = No education, Category $2=$ FLSC, 
category 3 = O-level / Probatoire, category 4 = A-level and above.

\section{Presentation and Discussion of Findings \\ 4.1 Poverty Incidence}

In order to estimate the poverty incidence of the two localities, we used the minimum wage in Cameroon. More precisely, the incidence of poverty was simply determined by the fraction of the sample earning less than the national minimum wage (36270 FCFA). Results of the overall incidence of poverty as well as that of the two localities are summarised in table 1 below.

Table 1: Poverty Incidence in Ndop and Soulede-Roua

\begin{tabular}{|c|c|c|c|c|}
\hline Variables & Categories & Obs. & Actual observations & Percentages \\
\hline \multirow{3}{*}{ Incidence of Poverty } & Overall & 300 & 218 & $72.67 \%$ \\
\cline { 2 - 5 } & Ndop & 150 & 145 & $96.67 \%$ \\
\cline { 2 - 5 } & Soulede-Roua & 150 & 73 & $48.67 \%$ \\
\hline
\end{tabular}

\section{Source: Computed by the authors}

Results from table 1 above reveal that the overall incidence of poverty in the two localities under study is estimated at $72.67 \%$. Comparatively, poverty incidence in Ndop was higher than that of Soulede-Roua as the values were calculated at $96.67 \%$ and $48.67 \%$ respectively. This might not reflect the true picture on ground. However, these figures may be accounted for by the selection of the participants in the Social Safety Net Programme which might have been more rigorous in Ndop and therefore the poorest of the poorest were mostly selected.

\subsection{Problems Associated with the Safety Net Programme}

As any other programme, the social safety net programme faced a number of constraints which compromised the success of the programme. Table 2 below summarises respondents' perception of the extent to which certain problems compromised the success of the safety nets programme in the study areas.

Table 2: Constraints Faced by the Safety Net Programme

\begin{tabular}{|c|c|c|c|c|c|}
\hline Items & $\begin{array}{l}\text { Strongly } \\
\text { agree }\end{array}$ & Agree & Undecided & Disagree & $\begin{array}{l}\text { Strongly } \\
\text { disagree }\end{array}$ \\
\hline Contribution to buy bike for coordinator & $\begin{array}{c}291 \\
(97 \%)\end{array}$ & $6(2 \%)$ & $0(0 \%)$ & $3(1 \%)$ & $0(0 \%)$ \\
\hline Cleaning of public offices by beneficiaries & $\begin{array}{c}207 \\
(69 \%) \\
\end{array}$ & $\begin{array}{c}7 \\
(2.3 \%) \\
\end{array}$ & $2(0.7 \%)$ & $\begin{array}{c}81 \\
(27 \%) \\
\end{array}$ & $3(1 \%)$ \\
\hline Late payment of money to beneficiaries & $\begin{array}{c}110 \\
(36.7 \%) \\
\end{array}$ & $\begin{array}{c}11 \\
(3.7 \%) \\
\end{array}$ & $\begin{array}{c}73 \\
(24.3 \%) \\
\end{array}$ & $\begin{array}{c}89 \\
(29.7 \%)\end{array}$ & $\begin{array}{c}17 \\
(5.7 \%) \\
\end{array}$ \\
\hline Provision of equipment in place of money & $\begin{array}{c}22 \\
(7.3 \%) \\
\end{array}$ & $\begin{array}{c}4 \\
(1.3 \%) \\
\end{array}$ & $9(3 \%)$ & $\begin{array}{c}82 \\
(27.3 \%)\end{array}$ & $\begin{array}{c}183 \\
(61 \%) \\
\end{array}$ \\
\hline Elimination of some beneficiaries unjustly & $\begin{array}{c}180 \\
(60 \%)\end{array}$ & $\begin{array}{c}13 \\
(4.3 \%)\end{array}$ & $2(0.7 \%)$ & $\begin{array}{c}11 \\
(3.7 \%)\end{array}$ & $\begin{array}{c}94 \\
(31.3 \%)\end{array}$ \\
\hline $\begin{array}{l}\text { Requirement of marriage certificate to be a } \\
\text { beneficiary }\end{array}$ & $\begin{array}{c}102 \\
(34 \%)\end{array}$ & $\begin{array}{c}51 \\
(17 \%)\end{array}$ & $\begin{array}{c}27 \\
(9 \%)\end{array}$ & $\begin{array}{c}2 \\
(0.7 \%)\end{array}$ & $\begin{array}{r}118 \\
(39.3 \%)\end{array}$ \\
\hline $\begin{array}{l}\text { Imposition of fine to beneficiaries who stay } \\
\text { away from community work }\end{array}$ & $\begin{array}{c}176 \\
(58.7 \%)\end{array}$ & $\begin{array}{c}11 \\
(3.7 \%)\end{array}$ & $\begin{array}{c}72 \\
(24 \%)\end{array}$ & $9(3 \%)$ & $\begin{array}{c}32 \\
(10.7 \%)\end{array}$ \\
\hline
\end{tabular}

Source: Field Survey, 2017.

Results from table 2 above reveal that the quasi totality of the respondents agreed with the fact that contribution to buy bikes for coordinators compromises the success of the safety net programme. In fact such contributions definitely reduce funds available for household who were already considered as poor. In addition, the greater majority of the respondents also claimed that the cleaning of public offices by beneficiaries hindered the success of the programme as $71.3 \%$ of the respondents agreed while just $28 \%$ disagreed. There seems to be a balance in respondent's perception of late payment of money to beneficiaries as a constraining factor to the success of the safety nets programme. More precisely, $40.4 \%$ of the respondents agreed that it was a limiting factor whereas 35.4 disagreed.

Furthermore, most of the respondent disagreed with the fact that provision of equipment in place of money compromised the success of the programme as $88.3 \%$ of the sample disagreed as opposed to $8.6 \%$ of those who agreed. On the other side, $64.3 \%$ of the respondents reported that elimination of some beneficiaries unjustly compromised the success of the safety nets programme while $35 \%$ were of the opposite opinion. Also, $51 \%$ of the respondents claimed that the requirement of marriage certificate affect the programme negatively while $40 \%$ disagreed with the statement. Finally, 187 respondents $(62.4 \%)$ reported that the imposition of fine to beneficiaries who stay away from community work compromised the success of the programme while 41 of them representing 
$13.7 \%$ of the sample disagreed with the statement.

\subsection{Empirical Results}

In order to capture the probable effects of safety net programme on poverty in the two localities, we used a probit model and the results are summarised in table 3 below:

Table 3: The effect of safety net programme on poverty in Cameroon

\begin{tabular}{|c|c|c|c|c|}
\hline VARIABLES & CATEGORIES & $\begin{array}{l}\text { (Ndop) } \\
\text { Poverty }\end{array}$ & $\begin{array}{c}\text { (SouledeRoua) } \\
\text { Poverty }\end{array}$ & $\begin{array}{r}\text { (Combined) } \\
\text { Poverty }\end{array}$ \\
\hline \multirow[t]{2}{*}{ Locality } & \multirow[t]{2}{*}{ Ndop } & & & $2.295 * * *$ \\
\hline & & & & $(0.373)$ \\
\hline \multirow[t]{2}{*}{ SSNP } & \multirow[t]{2}{*}{ SSNP } & -0.308 & -0.464 & -0.479 \\
\hline & & $(0.421)$ & $(0.624)$ & $(0.319)$ \\
\hline \multirow{4}{*}{ Occupation } & \multirow[t]{2}{*}{ self-employed } & 1.143 & -2.298 & 0.601 \\
\hline & & $(1.109)$ & $(670.5)$ & $(1.495)$ \\
\hline & \multirow[t]{2}{*}{ Unemployed } & 1.096 & 4.340 & $2.168 * * *$ \\
\hline & & $(1.089)$ & $(670.5)$ & $(0.379)$ \\
\hline \multirow[t]{2}{*}{ Gender } & \multirow[t]{2}{*}{ Male } & -0.324 & -0.338 & -0.451 \\
\hline & & $(0.339)$ & $(0.396)$ & $(0.342)$ \\
\hline \multirow{7}{*}{ Age groups } & \multirow[t]{2}{*}{ age $<30$} & $-0.775^{*}$ & $1.140 * * *$ & -0.561 \\
\hline & & $(0.462)$ & $(0.436)$ & $(0.636)$ \\
\hline & \multirow[t]{2}{*}{ age[30-50] } & $1.442 * *$ & -0.400 & -0.161 \\
\hline & & $(0.625)$ & $(0.624)$ & $(0.527)$ \\
\hline & \multirow[t]{2}{*}{ age[51-80] } & $1.121^{*}$ & -0.561 & -0.219 \\
\hline & & $(0.606)$ & $(0.623)$ & $(0.536)$ \\
\hline & Monogamous & $1.560^{*}$ & $1.910 * *$ & 0.935 \\
\hline \multirow{7}{*}{ Marital status } & & $(0.940)$ & $(0.906)$ & $(0.688)$ \\
\hline & \multirow[t]{2}{*}{ Polygamous } & -0.324 & $2.037 * *$ & 0.899 \\
\hline & & $(0.339)$ & $(0.958)$ & $(0.749)$ \\
\hline & \multirow[t]{2}{*}{ Divorced } & $1.362^{*}$ & $1.983 *$ & 0.395 \\
\hline & & $(0.820)$ & $(1.093)$ & $(0.846)$ \\
\hline & \multirow[t]{2}{*}{ Widowed } & 0.449 & $2.706^{* * *}$ & $0.976^{* *}$ \\
\hline & & $(0.455)$ & $(1.031)$ & $(0.426)$ \\
\hline \multirow{8}{*}{ Household size } & \multirow[t]{2}{*}{ Size $[1-5]$} & 1.154 & 1.154 & $2.461 * *$ \\
\hline & & $(0.800)$ & $(9.482)$ & $(0.965)$ \\
\hline & \multirow[t]{2}{*}{ Size [6-10] } & $1.776^{* *}$ & 1.067 & $2.266^{* *}$ \\
\hline & & $(0.864)$ & $(4.892)$ & $(0.960)$ \\
\hline & \multirow[t]{2}{*}{ Size [11-15] } & 0.696 & 0.985 & 1.519 \\
\hline & & $(0.428)$ & $(2.798)$ & $(1.050)$ \\
\hline & \multirow[t]{2}{*}{ Size [16-20] } & 1.215 & 0.449 & 1.206 \\
\hline & & $(0.937)$ & $(0.844)$ & $(1.275)$ \\
\hline \multirow{6}{*}{ Level of education } & \multirow[t]{2}{*}{ No education } & $2.982 * *$ & 0.797 & $0.717 * * *$ \\
\hline & & $(1.240)$ & $(0.885)$ & $(0.249)$ \\
\hline & \multirow[t]{2}{*}{ FSLC } & 0.866 & -0.615 & 0.498 \\
\hline & & $(0.519)$ & $(0.980)$ & $(0.832)$ \\
\hline & \multirow[t]{2}{*}{ Probatoire } & -0.652 & -1.525 & 0.00342 \\
\hline & & $(0.716)$ & $(1.093)$ & $(0.909)$ \\
\hline Constant & Constant & -1.244 & -7.951 & -2.366 \\
\hline & & $(1.311)$ & $(670.5)$ & $(1.666)$ \\
\hline & Observations & 150 & 150 & 300 \\
\hline
\end{tabular}

Note: Standard errors in parentheses; ${ }^{* * *} \mathrm{p}<0.01,{ }^{* *} \mathrm{p}<0.05,{ }^{*} \mathrm{p}<0.1$

Source: Computed by the authors

Results from the data analysis reveal that there is a negative but insignificant effect of participation in the safety net programme on poverty status in Ndop and SouledeRoua. Though the expected sign was recorded but the insignificance of the result can be attributed to some practical constraints that hindered the success of the programme. As revealed by table 3, respondents claimed that factors such as the contribution to buy coordinators' bike, cleaning of public offices by beneficiaries, late payment of money to beneficiaries, elimination of some beneficiaries unjustly and imposition of fine to beneficiaries who stay away from community work may have 
contributed in compromising the success of the programme. This result also conforms to the finding of Tendler and Serrano (1999) who claimed that, safety net programme have had insignificant impact in Latin America and Africa since the 1980s.

Furthermore, results from the combined analysis indicate that there is a positive effect of the size of the household on the likelihood of poverty. The results show that as the size household increases the coefficient of household size reduces. Though the sign is in conformity with our a priori expectation the decreasing marginal effect is surprising. In fact, literature mostly reveals that large family sizes are more likely to be poor giving the number of mouths to feed and to take care of. However, this result can be justified by the fact that the study was carried out in two rural areas where agriculture is the main occupation. Practiced with traditional techniques, agriculture is a labour intensive activity and large size families may be advantage in terms of labour. More labour will then increase agricultural production and reduce the likelihood of poverty.

There is positive and significant effect of Ndop locality on the likelihood of poverty meaning therefore that population from Ndop are more likely to be poor as opposed to those of SouledeRoua. This corroborates the results of the incidence of poverty which already suggested that poverty incidence in Ndop was higher than that of SouledeRoua. This result is significant at $1 \%$. This result is surprising but tenable. This can be explained by the fact that in the participants selected in Ndop may have included the poorest of the poor while it was not the case in SouledeRoua. Also, this finding can be backed by the movement of the population from remote areas to semi urban and urban areas. The spatial movement (migration) of population intensifies poverty in urban areas more than rural areas. This result is somehow similar to the findings of Njong (2008) who discovered that between 1996 and 2001, the incidence of poverty had risen in urban areas while stagnating in rural areas.

Additional results also indicated that there is a positive and significant effect of unemployment on the probability of being poor. This outcome conforms to our a priori expectation. In fact, an unemployed individual finds it difficult to sustain an income to finance his/her expenditure and therefore basic social needs.

The results also showed that people with no educational level are more likely to be poor as the coefficient of no education is positive and significant. This result is in line with our a priori expectation. In fact, according to spencer theory, education is one if not the most important determinant of labour force participation. Without education, an individual is less likely to join the labour force and consequently to earn income to finance basic needs. Furthermore, the vicious cycle of poverty can be used to illustrate this result. Poverty leads to low educational attendance which contributes to intensify further poverty. This result is in line with the finding of Siegel and Alwang (1999) who found that poverty pushes people to adopt poverty coping strategies which contributes in maintaining the poor in poverty. Such coping strategies may include dropping out of school in order to do mean jobs for survival.

Further results also revealed that there is a significant effect of matrimonial status on the likelihood in favour of poverty. More precisely, divorced and widowed were found to be more likely to be poor as compared to other matrimonial statuses. In fact, divorced and widowed do have the support they formerly had from their spouses and this plunges them into more poverty.

\section{Conclusion and policy implications}

This paper set out to examine the effects of the Social Safety Net Programme on poverty outcomes in Ndop and Soulde-Roua, two localities of Cameroon. Using primary data collected with the aid of a structured questionnaire administered to 300 participants of the programme. The probit model was used to conduct the analysis alongside some descriptive analysis. A combined analysis was conducted after the locality level analysis where a single probit model was performed for each of the localities. The overall poverty incidence was estimated at $72.67 \%$ and poverty incidence in Ndop was higher than that of Soulede-Roua as the poverty incidence in the two localities were respectively $96.67 \%$ and $48.67 \%$. The empirical results also confirmed the above result as the programme in the Ndop locality was found to exert a positive and significant influence on the likelihood to reduce poverty. Furthermore, participation in the safety net programme was found to have a negative effect on poverty though the coefficient was statistically insignificant. A key determinant of poverty in the localities of Ndop and SouledeRoua is Unemployment as it increases significantly the probability of poverty. Also, household size, widowed and no educational level were found to influence the likelihood in favour of poverty positively and significantly.

In line with the above findings, an important conclusion is that there is need for the government to improve on the efficiency of the programme by overcoming all the challenges inherent to the pilot experiment. Practically, government should use a participatory approach by asking the beneficiaries what they think will better help them and see how they can reach a compromise. By so doing, participants' motivation will be aroused.

Secondly, careful selection of participants with special attention to widowed is necessary since they are more exposed to poverty than others. Proper selection of participants includes also age consideration and family size. Family planning Programme should be promoted to better explain the importance of quality of children rather than quantity. 
Also there is need to promote education among the rural population. Adult education should be intensified or implemented where it does not yet exist. Education will provide the rural population with more formal and decent work opportunities which will participate in reducing poverty.

\section{References}

Babantunde et al (2007), Graduation Determinants of productivity safety Net program beneficiary Households. A logistic Analysis, volume 8, issue 4.

Barrett B., Thomas Reardon, and Patrick Webb. (2004). Non-Farm Income Diversification and Household Livelihood Strategies in Rural Africa: Concepts, Dynamics, and Policy Implications. New York. Cornell University.

Berhamu G. and Holden C. (2003) "Evaluating the Impact of Conditional Cash Transfer

Berhanu, G., \& Swinton, S. M. (2003). Investment in soil conservation in northern Ethiopia: The role of land tenure security and public programme. Agricultural Economics, 29(1), 69-84.

Brock, P., S. Mertinez, and M. Rubio-Codina (1999).Investing Cash Transfers to Raise Long-Term Living Standards. World Bank Policy Research Working Paper 3994, August 2006.

Dercon, S., Krishnan, P., 2004. Changes in poverty in villages in rural Ethiopia: 1989- 95. In: Booth, A., Mosley, P. (Eds.), The New Poverty Strategies. Palgrave MacMillan, Basingstoke, pp. 172- 204.

Devereux, S. and Sabates-Wheeler, R. (2006).Transformative Social Protection. Working Paper Number 232. Brighton. Institute for Development Studies.

Diday, E.; Lemaire, J.; Pouget, J.; Testu, F. (1982) El'ements d'Analyse des Donn'ees. Dunod, Paris.

Foko, Y.L, W.L. Parish, R.J. Willis (2007) "Sons, Daughters, and Intergenerational Support in Taiwan." American Journal of Sociology 99(4), pp. 1010-1041.

Gilligan, J. And Hoddinott (2007) Theory of Fertility Decline. London: Academic Press.

Gilligan Daniel O., John Hoddinott and AlemayehuSeyoum (2008). The impact of Ethiopiaes productive safety net programme and its linkages. IFPRI: Washington DC.

Holzman, S., Jorgensen, M., (2000). Multiple stressors in Southern Africa: the link between HIV/AIDS, food insecurity, poverty and children"s vulnerability now and in the future. Aids Care (S1):28-33.

INS (2002). Health Insurance Coverage in the United States, 2002 Demographic Programs Current population Reports. Consumer income. Issued September 2003, pp 60-223.

JuditS.and Matt H. (2011). Leaving No One Behind. Productive Safety Net and Household Building Programme. Ethiopia, United Printers Plc.

MIT,Harvard

Narayan, D. , Robert C., Meera K. Shah, and Patti P.. (1999). Voices of thePoor: Crying Out for Change. World Bank Series. Oxford: Oxford University Press.

Nguetse-Tegoum, Pierre (2011) "Pauvreté et vulnérabilité des ménages au Cameroun.” Mimeo, World Bank, Yaoundé, Cameroon.

Ningaye p. And Armand N. (2007) Le Village Camerounais à l'Heure de l'Ajustement.

Njong, A. M.(2008). "Investigating the Effect of Foreign Direct Investment on Export Growth in Cameroon: Final Paper Submitted to UNECA for the 24-25 November, at Addis Ababa, Ethiopia," . http://www.uneca.org/eca programmes/trade and regional integration/documents/Macro24nov08/FDI\%20and\%Export \% $20 \mathrm{Njong} \% 201 \mathrm{pdf}$

Norton, A., A. Ahmed, and F. Lund (2000).Linking Safety Nets, Social Protection, and Poverty Reduction Directions for Africa. Brief prepared for the conference on Assuring Food and Nutrition Security in Africa by 2020: Prioritizing Actions, Strengthening Actors, and Facilitating Partnerships, held in Kampala, Uganda, April - 2004

Paris: Karthala. Coussy, J. and J. Vallin. 1996. Crise et Population en Afrique. Crises économiques, Politiques d'Ajustement et Dynamiques Démographiques. Paris: CEPED. DHS. 2003. Fosterage rates calculated using the STAT compiler at the Demographic and Health

Programme." World Bank Research Observer 20 (1): 29-55. World Bank. 2011a. "Cameroon: Social Safety Nets." Vol 23 pg 31- 40

Siegel, P. B., \& Alwang, J. (1999). An Asset-Based Approach to Social Risk Management: A Conceptual Framework.

Sosina, A. U. and C. Ninno (2007). Food for Education Programme in Bangladesh: An Evaluation of the Impact on Educational Attainment and Food Security. International Food Policy Research Institute Discussion Paper 138. Washington DC: International Food Policy Research Institute.

Stewart and Van der Guest (1995). Rural development and poverty reduction: Is agriculture still the key eee ESA working paper no 07,02 June 1995

Tachi, T. D.(2003). "A Transaction Cost Analysis of Factors Affecting Market Arrangements in the Agro forestry Tree product value chain in Cameroon ${ }^{\text {ecee }}$. Esa Working Paper. N0. 09, $4^{\text {th }}$ January 2003. 
Tendler, J and J. Serrano, 1999, Social funds. What are they a model of?, mimeo,

Tsafack D. (2013), the role of social Programme in reducing poverty in Cameroon, poverty - inequality study, World Bank group Cameroon, issue 31-39.

World Bank (2000). Poverty in an Age of Globalisation, World Bank, Washington DC.

World Bank (2003). Social protection safety net project and poverty reduction in rural areas. The World Bank Group, Human Development Network, Washington DC. 